\title{
A Comparative Study on the Effects of Trigger Point Release vs Myofascial Release for Myofascial Trigger Points of Upper Trapezius in Smartphone Users
}

\author{
Anjali Suresh ${ }^{1 *}$, Rama Chandra L. A. ${ }^{2}$ and Prasanna Mohan ${ }^{3}$ \\ ${ }^{1}$ Research Scholar, Department of Physiotherapy, Garden City University \\ $16^{\text {th }}$ K.M old Madras Road, Virgo nagar Post, Bangalore-560049 \\ ${ }^{2}$ Assistant Professor, Department of Physiotherapy, Garden City University \\ $16^{\text {th }}$ K.M old Madras road, Virgo nagar Post, Bangalore-560049 \\ ${ }^{3}$ Associate Professor, Department of Physiotherapy, Garden City University \\ $16^{\text {th }}$ K.M old Madras Road, Virgo nagar Post, Bangalore-560049 \\ *Corresponding Author E-mail: anjali.mpt@gmail.com \\ ORCID No: https://orcid.org/0000-0001-6514-9840
}

\begin{abstract}
Background/aim: The increasing use of smartphone in daily life has brought about numerous musculoskeletal problems. Impairments in the neck is the most common when compared to other parts of the body. The aim of this study was to compare the effects of two different manual treatment techniques in two separate groups, i.e., trigger point release and Myofascial release (MFR) on the trigger points (TrPs) in the upper trapezius muscle in smartphone users. Both group received Ultrasound therapy. The smartphone addiction scale -short version was administered to all participants to determine the level of addiction and those who scores were high were included in the study. The set criteria in the study included the pain intensity on the visual analogue scale (VAS) neck disability using the Neck Disability Index and Cervical Range of motion side flexion using cervical goniometer.
\end{abstract}

Subjects and methods: This clinical trial study assessed the outcome measures within and between groups before, after the intervention and a follow up was done after 15 days. The target population were smartphone users between the age group of 18 to 35 years. 106 subjects ( 48 males, 53 females) participants who had been selected from among the eligible participants of 176 and who had TrPs in their upper trapezius muscle.

Results: The effect of Trigger point release and Myofascial release on patients of each groups with TrPs in the upper trapezius muscle resulted in increased cervical lateral flexion $(\mathrm{P}<0.001)$, decreased pain intensity on VAS $(\mathrm{P}<0.001)$ and decreased decrease in Neck disability $(\mathrm{P}<0.001)$ within the groups and between the group there was no significance.

Conclusion: Both manual techniques Trigger point release and Myofascial release reduced the symptoms of TrPs in the upper trapezius in both the groups equally, neither technique being superior to the other.

Keywords: myofascial release; trigger points; upper trapezius muscle; smartphone users; trigger point release

\section{INTRODUCTION}

In the present era of digitalization, smartphones have become an important tool in everyone's day to day life and the number of smartphone users have progressively increased worldwide. Many at times the smartphone users handle the device for internet, chatting, social networking and documentation, and other tasks, (mobile mail, games, media players, phone calls, text - editing capabilities) in a repeated manner throughout the day. Smartphones are widely used now a day to complete learning activities in academic institutions, and the use and development of mobile applications are rising. According to TRAI the number of wireless subscribers is $1,160.59$ million as against the population of 1.33 billion. The values give us an idea regarding increasing popularity of usage of smartphones in India. The use of electronic devices has both pros and cons. [1-4] Several studies have shown that more the usage of electronic devices more is the possibility of developing musculoskeletal symptoms. [5-8] This continuous and repeated use on a small device requires compromise of body structures and positions which can result in musculoskeletal disorder of the neck, upper extremity, and low back. Population based surveys have shown lifetime prevalence of neck pain between $67 \%$ and $87 \%$ [1]. Pain in the Trapezius muscle occurs due to stress and is the most common musculoskeletal disorder which leads to long and serious disability. The upper trapezius muscle is highly susceptible to overuse as it is a postural muscle $[9,10]$ 
Due to continuous contraction of the muscle knots in the muscles are created due to overload.These are known as trigger points leading to pain [10,11]. Myofascial trigger point is most found in the midpoint of upper border of trapezius [10]. Tenderness and knots are felt on palpation in the belly of the muscle. [12].

A tight muscle reduces the range of neck movements. Neck pain and restricted movements give a subjective feeling of stiffness which further increases the pain and results in muscle spasm, increases the soft tissue tightness, with an ensuring pain-spasm cycle which can be difficult to break $[9,12]$. It is essential to provide relief and to improve the function. Physiotherapy is the choice of treatment for trapezius muscle pain which includes many different treatment techniques such as massage, stretching etc., along with various modalities like Ultra sound, interferential therapy, transcutaneous, heat application, cryotherapy, and active treatment such as exercise therapy. There are various other soft tissue manipulation techniques like Positional Release Therapy (PRT), Muscle Energy Technique (MET), ART, MFR etc., which are also used for relief of muscle pain \& spasm [13].

This study compared the effectiveness of two techniques i.e., trigger point release and MFR. In trigger point release, ischaemic compression using deep digital pressure is applied over the tender point (trigger point) in a shortened position of the muscle This will break the adhesions [14,15]. Myofascial Release (MFR) is a soft tissue mobilisation technique. It can be defined as "the facilitation of mechanical, neural and psychophysiological adaptive potential as interfaced via the myofascial system [10]. Robert Ward, an osteopath, is attributed with coining the term MFR in the 1960s. MFR therapy involves specifically guided long duration mechanical forces which is of low load which manipulates the myofascial complex, these techniques restore optimal length, decreases pain, and improves function [13]. In MFR along with the manual traction, prolonged stretching of the fascia results in muscle to break down the adhesions, thus helps to decrease the pain and increase flexibility and thereby increase ROM [16]. There are many studies which shows the effectiveness of both the techniques either individually or with some other technique but there is dearth in the literature comparing the effectiveness between two techniques TrP release and MFR in patients with myofascial trigger point in the upper trapezius in smartphone users. [17]. Therefore, the aim of the study was to compare the effect of both techniques on cervical range of motion side flexion, pain, and neck disability in smartphone users with myofascial trigger points of upper trapezius muscle.

\section{MATERIALS AND METHODS}

This was a randomised interventional study, Before the commencement of this study, ethical approval was sought and obtained from the Ethical Committee of Garden City University. The participants were informed about the nature of the study and an informed consent form was taken from them. Thereafter, the pre assessment and assessment procedures were carried out, and the participants who met the inclusion criteria were a part of the study. The outcome measures were Visual Analogue Scale (VAS), Neck disability index (NDI) and cervical Range of side flexion (CROM-SF). Smartphone assessment Scale -short version was administered to all the participants who volunteered for this study. A total 179 participants between the age group of 18 to 35 years of age were assessed for eligibility, 69 participants were excluded from the study as they did not fulfil the inclusion criteria and 110 participants were a part of this study. There were 2 dropouts in each group and in total 4. The data was analysed for 106 participants. Participants having radiculopathy, neck and back deformities like torticollis or scoliosis, history of trauma or fracture or surgery in the neck or upper back or shoulder, any skin diseases in the trapezius, those who were on anticoagulation therapy, long term corticosteroid therapy any sensory disturbance in the trapezius area, those who had taken analgesic in the last 24 hours were excluded from the study.

SCREENING TOOL 1. Demographic data including name age, gender, number of hours of usage of smartphone and number of years of using smartphone 2. Smartphone Addiction Scale-Short Version (SAS-SV): The SAS-SV questionnaire (English version) is a tool for assessing smartphone addiction level. This 10-item self-reported scale addresses 5 content areas or domains, as follows: (i) daily-life disturbance, (ii) withdrawal, (iii) cyberspace-oriented relationships, (iv) overuse, and (v) tolerance. Participants respond on a 6-point Likert scale ranging from 1 ("strongly disagree") to 6 ("strongly agree") based on self-reporting. The total score in the SAS-SV is 60, with an average score of 30. It identifies the different range for males and females. If the score was higher than 31 , then the men are addicted to smartphones. If the scores were between 22-31 there is a high risk of addiction to smartphones. If the score was higher than 33, then the women are addicted to smartphones. If the scores were between 22-33 there is a high risk of addiction to smartphones.

They were divided into two groups, Group A and Group B, with 55 subjects in each, through randomisation using lottery method. The participants were single blinded of the treatment they received. Group A received trigger point release in the form of ischaemic compression and group B received MRF. Both groups received Ultrasound therapy. Cervical ROM side flexion, NDI and VAS were used as outcome measures. [18,19].

Group A - Subjects were administered Trigger point release by Ischemic compression and were placed in supine position on the couch with the head fully on the surface of the couch, to reduce tension in the upper trapezius muscle. Arm was positioned in slight shoulder abduction with the elbow bent and their hand resting on their stomach. To perform Trigger point release to the upper trapezius, the researcher stood at the head end of the couch. Technique First, using a pincer grasp the muscles was palpated over the fibres of the upper trapezius. To locate a trigger point, the muscle was palpated to feel for a taut band or a twitch response in the muscle belly. A common location of upper trapezius trigger points is in the middle of the muscle belly, approximately 1 to 2 inches medial to the acromion process of the scapula. Once the trigger point was located, IC was applied gradually by applying pressure to the trigger point with the thumb and index finger. In the case when more than one MTrP was detected, the most symptomatic was evaluated. The researcher was in communication with the patient, checking to ensure that the compression is within the limits of pain tolerance. The procedure was held for approximately 20 seconds to 60 seconds. The patient then informed the researcher about the decrease in pain, or until the muscle fibers begin to relax under pressure of the researcher. [20] Once the release was felt, the pressure was released gradually. Then effleurage strokes were done to flush out the area and followed with a passive stretch to the muscle. This was repeated for three to five times for six days. 
Group B subjects received Myofascial release with the patient sitting on a chair and arms supported on thighs. The researcher stood behind the subject on the affected side. The tender area was marked with a nontoxic marker. Forearm and/or ulnar border of the palm was used to apply pressure and glide medially towards the base of the neck and/ or towards the upper scapular region. As the glide was being given, the subject was asked to side bend the head to the opposite direction while sitting in an erect position. Myofascial release was given for 3-5 minutes which included 3 palmar glides [21]. Ultrasound- It is a non-invasive method which consists of piezoelectric crystals that convert the electrical energy to mechanical oscillation energy using high-frequency alternating current. Therapeutic ultrasound: applied to the trapezius muscle was in the Pulse Mode-- 1.2 watts/ $\mathrm{cm}^{2}$.Treatment time- 5 mins, Frequency of $1 \mathrm{MHz}$, patient positionsitting with back and arm rest. [22,23].

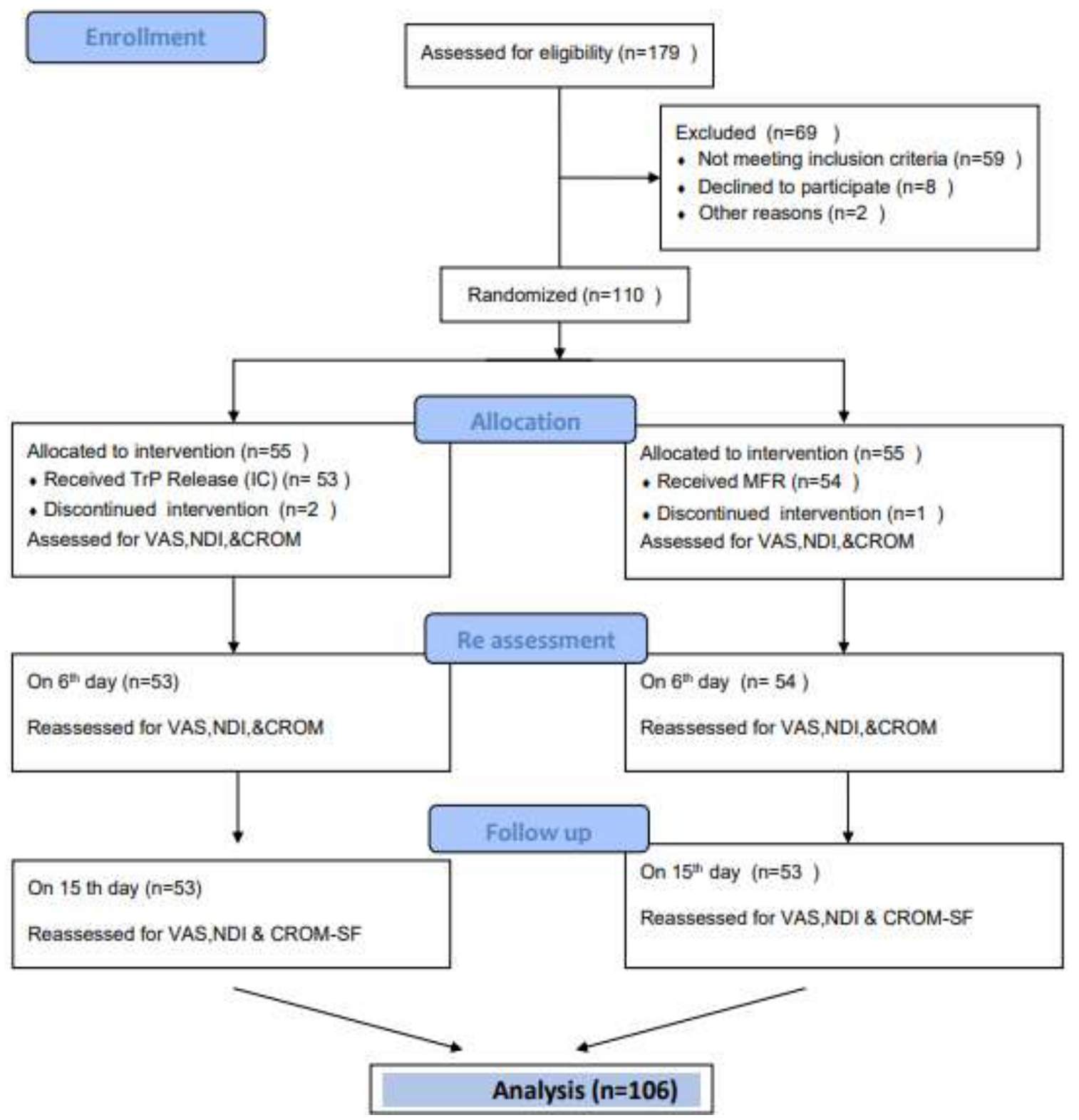

FIG/TABLE 1: Consort Flow Chart

Upper trapezius stretch was advised as home program for patients of both groups. The VAS score, cervical range of motion side flexion using a goniometer, and the neck disability index were calculated for the pretest and on the $6^{\text {th }}$ day of the post treatment and on the follow up day. On the last day of the treatment session, a handbook with the right ergonomic postures was given to the subjects and a follow up was done on the $15^{\text {th }}$ day.

\section{RESULTS}

Results were analysed using SPSS software version 22.0 and Descriptive statistics mean (SD), were used to depict the profile of study population. Comparison within groups and between groups were done for VAS, NDI and CROM SF was done for the pre-test, post-test and follow up measurements using ANOVA.

The study comprised of 50(47\%) male and 56(53\%) in total. While group A had 25 males and 28 females, Group B too has the same number the mean age of the subjects in both the groups was 27.22 and 26.84 respectively. Both the techniques showed significant improvement in all the various parameters like cervical ROM, NDI, and pain on VAS. 


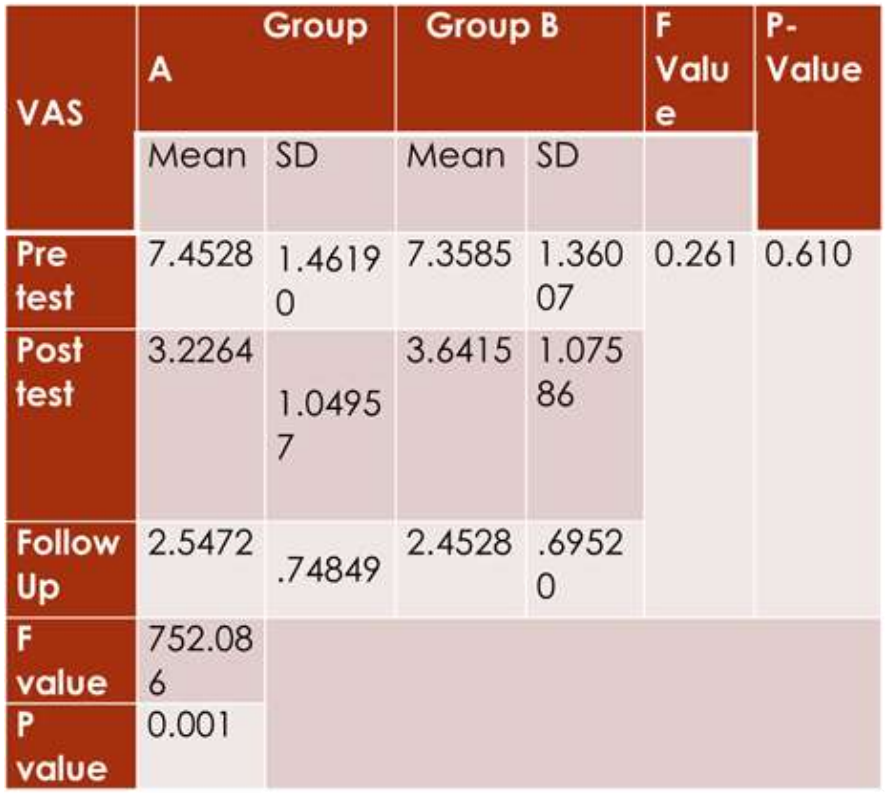

TABLE/FIG 2: Mean and Standard deviation of VAS for pre, post and follow up for group A and B and level of significance within and between groups

\begin{tabular}{|c|c|c|c|c|c|c|}
\hline \multirow{2}{*}{ NDI } & \multicolumn{2}{|c|}{ Group A } & \multicolumn{2}{|c|}{ Group B } & \multirow{2}{*}{$\begin{array}{l}F \\
\text { value }\end{array}$} & \multirow{2}{*}{$\begin{array}{l}\text { P. } \\
\text { Value }\end{array}$} \\
\hline & Mean & SD & Mean & SD & & \\
\hline Pre test & 28.9811 & 1.79198 & 28.9118 & 3.00737 & .397 & .530 \\
\hline Post test & 21.1321 & 3.33995 & 22.7358 & 3.03248 & & \\
\hline Follow Up & 19.4528 & 1.79198 & 18.6415 & 1.64656 & & \\
\hline F value & 702.765 & & & & & \\
\hline P value & 0.001 & & & & & \\
\hline
\end{tabular}

TABLE/FIG 3: Mean and Standard deviation of NDI for pre, post and follow up for group A and B and level of significance within and between groups

\begin{tabular}{|c|c|c|c|c|c|c|}
\hline \multirow[b]{2}{*}{ CROM } & \multicolumn{2}{|c|}{ Group A } & \multicolumn{2}{|c|}{ Group B } & \multirow{2}{*}{$\begin{array}{l}\text { F } \\
\text { value }\end{array}$} & \multirow{2}{*}{$\begin{array}{l}P \text { - } \\
\text { Value }\end{array}$} \\
\hline & Mean & SD & Mean & SD & & \\
\hline Pre test & 28.4340 & 1.87606 & 28.9811 & 1.64656 & \multirow[t]{3}{*}{.023} & \multirow{3}{*}{.881} \\
\hline $\begin{array}{l}\text { Post } \\
\text { test }\end{array}$ & 37.0566 & 1.88532 & 36.6792 & 1.85818 & & \\
\hline $\begin{array}{l}\text { Follow } \\
\text { Up }\end{array}$ & 39.2830 & 1.75825 & 39.0000 & 1.77591 & & \\
\hline F value & 1354.382 & & & & & \\
\hline P value & 0.001 & & & & & \\
\hline
\end{tabular}

TABLE/FIG 4: Mean and Standard deviation of CROM-SF for pre, post and follow up for group A and B and level of significance within and between groups. 
DISCUSSION: This was a comparative study to compare the efficacy of TrP and MFR on myofascial trigger points of upper trapezius muscle in smart phone users. Both treatment techniques were found to be beneficial to participants. A follow up was done after 15 days. Ergonomic advice and a booklet were given to the subjects to follow. Both manual techniques involved.

The upper trapezius muscle is designated as a postural muscle susceptible to overuse. Taut bands in the trapezius muscle are the most common musculoskeletal disorder. It usually is caused by placing too much stress or strain over the trapezius muscle. Most smartphone tasks require users to stare sharply downwards or to hold their arms out in front of them to read the screen, which makes the head move forward and causes an excessive anterior curve in the lower cervical vertebrae and an excessive posterior curve in the upper thoracic vertebrae to maintain balance, placing stresses on the cervical spine and neck muscles [24].

There is general agreement that any kind of muscle overuse or direct trauma to the muscle can lead to the development of TrPs. Muscle overload is thought to be the result of sustained or repetitive low-level muscle contractions, eccentric muscle contractions, and maximal or submaximal concentric muscle contractions. There may be a disruption of the cell membrane, damage to the sarcoplasmic reticulum with a subsequent release of high amounts of calcium-ions [25].

The use of Ischaemic compression on trigger points echoed by many authors have proposed reduction in height of the sarcomeres and thus caused concomitant lengthening of the sarcomeres in the involved muscle fibres [19].

While in MFR, the gentle forces applied to the facial restrictions elicit vasomotor response and increase blood flow to the affected area, thereby enhancing lymphatic drainage of toxic metabolic wastes. It also realigns the facial planes, and most importantly resets the soft tissue proprioceptive sensory mechanism. This latter factor reprograms the central nervous system, enabling a normal functional range of motion without eliciting the old pain pattern [26].

Hugh Gemmell et al, conducted a randomized single blind placebo-controlled trial to find the immediate effect of ischaemic compression and trigger point pressure release on neck pain and upper trapezius trigger points. trigger point release with sham ultrasound (SUS). He concluded that a single treatment with ischaemic compression to an active upper trapezius TrP was found to be superior to SUS [27].

Albert F. Moraska et al., conducted a biomedical research to measure the physiological changes within an active myofascial trigger point (MTrP) undergoing trigger point release (ischemic compression) where the Interstitial fluid was sampled continuously at a trigger point before and after intervention. They concluded that changes in cellular metabolism occur abruptly and remain elevated within an active MTrP following trigger point release. Dialysate lactate, and to a lesser extent dialysate glucose, concentration increased in the MTrP in the 20 minutes following trigger point release Local nutritive blood flow (microvascular exchange) was similarly increased. changes in cellular metabolism occur abruptly and remain elevated within an active MTrP following trigger point release. Dialysate lactate, and to a lesser extent dialysate glucose, concentration increased in the MTrP in the 20 minutes following trigger point release Local nutritive blood flow (microvascular exchange) was similarly increased. e. In keeping with the integrated hypothesis of a trigger point proposed by Simons, the zone around a MTrP is in an ischemic state resulting in a shortage of glucose and oxygen for metabolism [15].

The current data support this hypothesis, in that upon relaxation of the trigger point nodule, nutritive blood flow to the tissue is enabled, allowing for increased substrate perfusion and oxygen delivery to skeletal muscle to meet cellular energy demands required to regain homeostasis [28].

Paul J et al., who compared the effect of MFR and deep transverse friction massage for upper trapezius trigger point, explained that MFR improves the vertical alignment and lengthens the body providing more space for proper functioning of osseous structures, nerves, muscles, blood vessels and organs which improves the function [26]. Barnes MF claimed that because of MFR, there is change in the viscosity of the ground substance of the muscle and fascia which can restore proper alignment of the muscle fibre and increase the joint mobility. He explained that MFR made the fascia elongated, softened and more pliable thereby, helping to restore the normal length of the fascia. Thus, it can be helpful to increase the flexibility and joint ROM [28,29]. The resultant muscle relaxation may encourage a copious return of blood and oxygen, which dramatically elevates pain threshold and encourage healthy, compliant tissue. This promotes healing, reduces pain and pressure in the fibrous band of connective tissue or fascia by breaking up the adhesions.

This may be the first study which compares the effectiveness of these two techniques in pain due to trapezius spasm. In the present study both the techniques TrP release MFR were found to be effective. The techniques worked on the trigger point effectively. In TrP release the nutritive blood flow to the tissue is enabled, allowing for increased substrate perfusion and oxygen delivery to skeletal muscle to meet cellular energy demands required to regain homeostasis and in MFR the is change in the viscosity of the ground substance of the muscle and fascia which can restore proper alignment of the muscle fibre and increase the joint mobility. This in turn brings increased return of blood and oxygen, which elevates pain threshold and encourage healthy, compliant tissue thereby promoting healing reducing pain and breaking the adhesions. This result relieved the symptoms giving quick and long-lasting effect with regards to pain, mobility, and improvement of neck function. As a result, the scar tissue adhesions are broken and spasm is relieved due to shortening and lengthening of muscle thereby, giving quick and long-lasting effect with regards to pain, mobility, and improvement of neck function.

LIMITATION: The limitation of the present study was that long term follows up was not taken to see the sustained effect of therapy.

CONCLUSION: Both techniques are effective in alleviation of symptoms, associated disability and increasing range of motion of the cervical side flexion in subjects with trigger points of upper trapezius muscle who are smartphone addicts. 
ACKNOWLEDGEMENT: We sincerely acknowledge all the participants who volunteered for this interventional study.

\section{REFERENCES}

[1] Desai MJ, Saini V, Saini S. Myofascial pain syndrome: a treatment review. Pain Ther. 2013;2(1):21-36. doi:10.1007/s40122-013-0006-y

[2] Marc S Micozzi, Fundamentals of Complementary and alternative, Elsevier Saunders 2015286

[3] Stecco C, Macchi V, Porzionato A, Duparc F, De Caro R. The fascia: the forgotten structure. Ital J Anat Embryol. 2011;116(3):127-38.

[4] Cagnie B, Castelein B, Pollie F, Steelant L, Verhoeyen H, Cools A: Evidence for the use of ischemic compression and dry needling in the management of trigger points of the upper trapezius in patients with neck pain: a systematic review. Am J Phys Med RehabSil 2015; 94:573

[5] Simons DG, Travell JG, Simons LS. Myofascial pain and dysfunction: the trigger point manual. Vol 1, upper half of body. 2nd ed. Baltimore: Williams \& Wilkins; 1999.

[6] Langevin HM, Fox JR, Koptiuch C, Badger GJ, Greenan-Naumann AC, Bouffard NA, et al., Reduced thoracolumbar fascia shear strain in human chronic low back pain. BMC Musculoskeletal Disorders .2011, 12:203

[7] Ajimsha, M. S., Effectiveness of direct vs indirect technique myofascial release in the management of tension-type headache. Journal of bodywork and movement therapies, 2015 (4), 431-435.

[8] Day JA, Stecco C, Stecco A., Application of fascial manipulation technique in chronic shoulder pain anatomical basis and clinical implications. J Body Mov Ther.2009 13:128-35

[9] Ravish VN, Helen S. To compare the effectiveness of myofascial release technique versus positional release technique with laser in patients with unilateral trapezitis. Journal of Evolution of Medical and Dental Sciences. 2014;3(9):2161-67.

[10] Chaudhary ES, Shah N, Vyas N, Khuman R, Chavda D, Nambi G. Comparative study of myofascial release and cold pack in upper trapezius spasm. International Journal of Health Sciences and Research (IJHSR). 2013;3(12):20-27.

[11] Hermans V, Spaepen A. Perceived discomfort and electromyographic activity of the upper trapezius while working at a VDT station. International Journal of Occupational Safety and Ergonomics. 1995;1(3):208-14

[12] de las Peñas CF, Campo MS, Carnero JF, Page JC. Manual therapies in myofascial trigger point treatment: A systematic review. Journal of Bodywork and Movement Therapies. 2005;9(1):27-34.

[13] Manheim CJ. The myofascial release manual. Slack Incorporated; 2008

[14] Kage V, Ratnam R. Immediate effect of active release technique versus mulligan bent leg raise in subjects with hamstring tightness: a randomized clinical trial. Int J Physiother Res. 2014;2(1):301-04.

[15] Hammer WI, editor. Functional soft-tissue examination and treatment by manual methods. Jones \& Bartlett Learning; 2007.

[16] Altindag 0, Ozaslan S. Efficacy of myofascial release method on pain and disease severity in patients with fibromyalgia. J Pain Relief. 2014; 3:161.

[17] Sadria G, Hosseini M, Rezasoltani A, Bagheban AA, Davari A, Seifolahi A. A comparison of the effect of the active release and muscle energy techniques on the latent trigger points of the upper trapezius. Journal of Bodywork and Movement Therapies. 2017;21(4):920-25

[18] Shin YJ, Kim WH, Kim SG. Correlations among visual analogue scale, neck disability index, shoulder joint range of motion, and muscle strength in young women with forward head posture. Journal of Exercise Rehabilitation. 2017;13(4):413.

[19] Travell JG, Simons DG. Myofascial pain and dysfunction: the trigger point manual. Lippincott Williams \& Wilkins; 1983

[20] Namwongsa S, Puntumetakul R, Neubert MS, Boucaut R. Factors associated with neck disorders among university student smartphone users. Work. 2018;61(3):367-378. doi: 10.3233/WOR-182819. PMID: 30373996

[21] Nambi GS, Sharma R, Inbasekaran D, Vaghesiya A, Bhatt U. Difference in effect between ischemic compression and muscle energy technique on upper trepezius myofascial trigger points: Comparative study. Int J Health Allied Sci $2013 ; 2: 17-22$

[22] Snehal Desai and Dr. Kiran Jeswani. To compare the effect of myofascial release and ischaemic compression on pain, cervical lateral flexion and function in acute Trapezitis in young adults. IJAR,2018; 4(3): 448-454. 
[23] Lukas D. Linde MSc Dinesh A. Kumbhare MD, MSc, FRCPC Maneil Joshi BSc John Z. Srbely DC, PhD Lukas D. Linde MSc The Relationship between Rate of Algometer Application and Pain Pressure Threshold in the Assessment of Myofascial Trigger Point Sensitivity. Pain Practice, Volume 18, Issue 2, 2018 224-229

[24] Fernández-de-las Penãs C, et al: The immediate effect of ischemic compression technique and transverse friction massage on tenderness of active and latent myofascial trigger points: a pilot study, J Bodyw Mov Ther 10:3-9, 2006

[25] Moraska AF, Hickner RC, Kohrt WM, Brewer A. Changes in blood flow and cellular metabolism at a myofascial trigger point with trigger point release (ischemic compression): a proof-of-principle pilot study. Arch Phys Med Rehabil. 2013;94(1):196-200. doi: 10.1016/j.apmr.2012.08.216

[26] Vásquez B, Navarrete J, Farfán E, Cantín M. Effect of pulsed and continuous therapeutic ultrasound on healthy skeletal muscle in rats. Int J Clin Exp Pathol. 2014;7(2):779-783. Published 2014 Jan 15.

[27] Gemmell, Hugh \& Miller, Peter \& Nordstrom, Henrik. (2008). Immediate effect of ischaemic compression and trigger point pressure release on neck pain and upper trapezius trigger points: A randomised controlled trial. Clinical Chiropractic. 11. 30-36. 10.1016/j.clch.2007.09.001.

[28] Barnes MF. The basic science of myofascial release: morphologic change in connective tissue. Journal of Bodywork and Movement Therapies. 1997;1(4):231- 38

[29] Paul J, Kumar M. A comparative study on the effect of Myofascial Release versus Deep Transverse Friction on myofascial trigger points of upper back. International Journal of Medical. 